\title{
The right treatment to the right patient at the right time
}

\section{E M H Haldorsen}

\section{A multitude of variables have been presumed to influence and predict return to work}

$\mathrm{n}$ an attempt to prevent a development to chronic pain (which concerns about $10 \%)$, occupational physicians and other health professionals should be able to identify patients with a high risk of chronic disability at an early stage. It is well known that the longer individuals are out of work, the less likely they are to return to work. A multitude of variables have been presumed to influence and predict return to work. The most commonly assessed predictors include medical factors, sociodemographic factors, job related information, and psychological variables. There has been growing recognition that the lack of consistency in reporting findings in this area may be due to the heterogeneity of the patients studied. In general, combinations of sets of predictors seem more important than single predictors.

The article by Hogg-Johnson and Cole in this issue ${ }^{1}$ is a methodologically strong addition to publications in this important field. In a prospective cohort of 907 injured workers (mean age 38.6 years; 49\% men; $59 \%$ back injuries, $27 \%$ upper limb injuries, and 15\% lower limb injuries), they have developed a model of prognosis predicting length of time receiving workers' compensation benefits using factors measured during the initial four weeks. The data were collected by telephone interviews, first at baseline (the first contact), then at 4, 10, 16, and 52 weeks post-injury. Workers were recruited at workers compensation claim registration. Outcome was duration on total temporary wage replacement benefits.

The authors found that body region specific functional status, change in pain, workplace offers of arrangements for return to work, and recovery expectations were independently predictive of time on benefits ( see table 5). Based on a risk score (the vector of selected variables), the patients were divided into six groups from very low risk to very high risk (see fig 2). At four months, only one third of the highest risk group had gone off benefits. In comparison, over $95 \%$ in the lowest risk group had done so.

It was surprising that the authors ended up with as many as six prognostic groups. In their predictive study among acute and subacute back pain patients, Linton and Hallden used three groups. In a randomised controlled study by Haldorsen et al, the patients, who were long term sick listed because of musculoskeletal pain, were divided into good, medium, or poor prognosis by using a standardised psychologicalphysiotherapeutic screening instrument. ${ }^{3}$ I think it is necessary to investigate this further on. How many prognostic groups are actually necessary for giving the right treatment to the right patient at the right time? Are there any sex differences concerning the characteristics of the patients in the different groups?

"How many prognostic groups are actually necessary for giving the right treatment to the right patient at the right time?"

There are several strengths in this study -investigation of early prognostic factors for chronic pain from acute pain, relatively large sample group, large number of variables included, and time dependent nature of potential prognostic factors have been taken into account, for example, "change in pain". On the other hand, the prognosis was measured by the patient's own report; the authors did not use any objective measures. I miss an explanation of why they chose not to include objective measures of functional capacity. Furthermore, the authors use a classification unknown to me of the different complaints (back pain, upper limb, and lower limb). What is meant by back pain, both upper and lower back? What about upper limb-do these patients also have neck pain? I also wonder whether the authors have available information about which type of treatment (if any) the patients have participated in during the follow up period.

In the last sentence of the discussion, the authors write: " ... these results may lead to interventions which will facilitate more rapid return to work ..." In our study we found that choice of treatment (ordinary treatment, light multidisciplinary, or extensive multidisciplinary treatment) was especially important for patients classified to have poor prognosis for return to work. Extensive multidisciplinary treatment for these patients seemed to be superior both from the patient's point of view, as well as from an economic perspective. The patients classified as having a good prognosis had no additional treatment effect measured by return to work by participating in an extensive multidisciplinary treatment programme. ${ }^{3}$

The results of prognostic studies give evidence for a better utilisation of the resources by performing an easy screening of the patients before treatment, and allocating the patients to adequate treatment. We found that mostly men (61\%) were classified as having a good prognosis, while women $(71 \%)$ were classified as having a medium or poor prognosis. In addition, we found that older patients were found to a greater extent to have poor prognosis, compared with younger patients. ${ }^{3}$ These findings are not supported by the study by Hogg-Johnson and Cole.

Hogg-Johnson and Cole $^{1}$ found that workplace offers of arrangements for return to work were predictive of time on benefits. Another study by Haldorsen et al showed that follow up meetings between supervisors and employees seemed to be important in enhancing work environmental changes and increasing the number of employees returning to work. ${ }^{4}$

Patients with low back pain constitute a heterogenous group and I believe that there never will be a single test or a single question that will work for all patients. Used in the right way a simple screening instrument can help health professionals better identify patients who may have poor prognosis for return to work, but we have to be flexible in the use of such an instrument. We must be aware of what and how we communicate to the patient, and what treatment we offer. Besides information and fear reduction, increasing activity despite pain, and frequent follow up seem to be important factors in handling chronic low back pain. ${ }^{5}$

The results of the study by HoggJohnson and Cole ${ }^{1}$ are interesting (also because of the statistical methods used) and need to be investigated further. A short screening instrument for identification of patients with different prognosis for return to work will also be of great value in the clinical guidelines for patients with low back pain.

Occup Environ Med 2003;60:235-236

\section{Author's affiliation}

E M H Haldorsen, Haukeland University Hospital, Bergen, Norway 
Correspondence to: Dr Psychol E M H Haldorsen, The Outpatient Spine Clinic, Haukeland University Hospital, Box 1, 5021 Bergen, Norway: ellen.haldorsen@haukeland.no

\section{REFERENCES}

1 Hogg-Johnson S, Cole DC. Early prognostic factors for duration on temporary total benefits in the first year among workers with compensated occupational soft tissue injuries. Occup Environ Med 2003;60:244-53.
2 Linton SL, Hallden KJ. Can we screen for problematic back pain? A screening questionnaire for predicting outcome in acute and subacute back pain. Clin J Pain 1998;14:209-15.

3 Haldorsen EMH, Grasdal AL, Skoven JS, et al. Is there a right treatment for a particular patient group? Comparison of ordinary treatment, light multidisciplinary treatment, and extensive multidisciplinary treatment for long-term sick-listed employees with musculoskeletal pain. Pain 2002;95 musculosk
4 Haldorsen EMH, Jensen IB, Linton SJ, et al Training work supervisors for reintegration of employees treated for musculoskeletal pain. J Occup Rehab 1997:7:33-43.

5 Skouen JS, Grasdal AL, EMH Haldorsen, et al. Relative cost-effectiveness of extensive and light multidisciplinary treatment programs versus treatment as usual for patients with chronic low back pain on long-term sick leave. Randomised controlled study. Spine 2002;27:901-10.

\section{LETTER FROM AUSTRALIA}

A s an ex-hippy and child of the 60s I had, in keeping with Bill Clinton and many Labour MPs, an early interest in plant pharmacology. I was, therefore, destined to become either a botanist or a pharmacologist, but instead, ended up as a clinical pharmacologist and latterly as a cardiologist. My interest in drugs is now, therefore, evidence based and ongoing, and until now has been on the right side of the law. Like my peers I took MRCP part I as part of my right of passage to higher things, so you would have thought that I was used to ticking the right box. Evidently not!

I recently travelled to Australia, as part of an ongoing collaboration with the Institute of Biomedical Engineering at the University of New South Wales Australia, and as such was carrying a number of pharmaceutical grade drugs. It is a trip I have made a number of times before without incident. I guess I should have been forewarned that this trip may be different when I arrived at check in to find my electronic visa was no longer valid. After a few phone calls this was rectified and I was on my way. The drugs I was carrying were not for human use but were destined to be administered to sheep. I know what you must already be thinking, why was someone from Wales travelling to Australia to experiment in sheep? That's another story.

Anyway, shortly before the plane landed in Sydney we were issued with landing cards with a number of boxes to tick. Any of you who tick these boxes on autopilot, as I did, beware. Question 2 asked whether I was bringing any drugs or medicines into Australia. The long flight had obviously numbed my brain and I took it to mean illicit drugs or medications for human use. Never for a moment did I think that the Australian customs would be excited by the drugs I was bringing with me to administer to sheep. I was half right. After $x$ raying the container I was asked about the drugs by the customs officials, who were polite and courteous throughout. I duly explained that they were not for human use and was allowed entry to Australia.

I was to discover that the ministry of Agriculture, Fisheries and Forestry Australia (AFFA) did not take quite the same view. There is not surprisingly much concern in Australia about foot and mouth disease, and when AFFA were informed by the customs officials they swung into action. Two days later I was about to give a lecture in Melbourne when I had a phone call to my room from a friend who had kindly booked my accommodation in Sydney before my arrival. He told me that I was about to get a call from a senior compliance officer from AFFA, about drug smuggling into Australia and not ticking the right box on my entry form. He assured me that this was not a joke, and anyway 1 April was still two weeks off. AFFA had turned up at my accommodation in Sydney while I was in Melbourne and also at the offices of my friend. They were apparently very anxious to speak to me!

on my return from Melbourne, my colleagues and I were interviewed not only by the compliance officers but also by a ministry vet. The major concern of AFFA being that the drugs may contain animal products and sheep are not classed as laboratory animals. Photographs were taken, both of the animal facilities and also the offending drugs. At this stage I felt destined to feature in the News of the World. Fortunately all the Australian officials were extremely professional and polite and the situation was resolved to everyone's satisfaction without the necessity of my having to serve a jail sentence. However, my colleagues and I had to give full and frank explanations, via e-mail, to the ministry offices in Canberra. Interestingly, the next day a colleague informed me that one of my recent papers was number 33 out of the top 50 papers visited on the Journal of the American College of Cardiology website. I have a feeling that my current position on the AFFA most wanted list was somewhat higher!

Apart from the reminder that travel for work purposes is stressful, with papers on this topic appearing in $O E M$ in recent months, this story illustrates the increased concerns these days about transporting animal and plant materials across borders. These concerns are justified. Uncontrolled importing of such materials can mean that infectious agents or pests are transferred between countries, with potentially very serious consequences, as in the case of the recent foot and mouth epidemic in the UK, probably related to unauthorised importing of contaminated meat. And the spectre of bioterrorism looms, particularly after the attack on the World Trade Center in September 2001 and the recent deliberate spread of anthrax in the US postal system.

My own story has a happy ending. Our studies went well and the day before I left I received official notification of my alleged breach of section 137.1 of the Criminal Code Act 1995, which in case you were wondering carries a maximum penalty of 12 months imprisonment. I remain deeply grateful for the kindness and professionalism shown to me throughout by the officials from AFFA, and you can rest assured that next time I return to Australia I will tick the right box!

July 2002

John R Cockcroft

Visting Professor, Graduate School of Biomedical Engineering, University of New South Wales, Sydney, NSW 2052, Australia 